\title{
ROLE OF INTERNATIONAL EDUCATIONAL PROJECTS IN SUPPORTING EUROPEAN INTEGRATION IN THE CONTEXT OF ROMANIA
}

Jacques BAZEN, PhD

Saxion University of Applied Sciences, Enschede, The Netherlands

j.c.bazen@saxion.nl

Florin DUMA, PhD

Faculty of European Studies, Babeș-Bolyai University Cluj-Napoca, Romania florin.duma@ubbcluj.ro

\begin{abstract}
This study is about the effects of short exchange projects on students from higher education. The authors observe a low willingness among students from The Netherlands and Romania to spend longer term exchange periods in each other's country. Just $0.3 \%$ of Dutch ERASMUS+ scholarship recipients went to Romania in 2017, and vice versa $1.8 \%$. Given the population sizes and higher education enrolment rates, the expected average would have been around $3 \%$ for both countries. Even though Romania's attractiveness of higher education is slowly increasing, the authors decided to try to help students with broadening their horizon by offering an educational intervention that consists of a short exchange project that consists of an actual business assignment for a client from either business or government. The results of the corresponding pre-and post-test indicates that students are probably a bit overly optimistic about their intercultural skills at the start, but at the end especially enjoy a lot the multidisciplinary approach of the exchange project.
\end{abstract}

Keywords: education, internationalization, project management, European integration.

\section{Introduction}

Romania acceded the European Union (EU) in 2007. This process of accession, and subsequent ever closer integration of Romania into the EU could not always be called smooth, as 
in several instances Romania was criticized by the EU about not always following through necessary policy reforms to comply with European rules and regulations. In spite of these political and judicial issues, when looking at educational cooperation, Romanian universities are more and more integrated in European networks, as can be seen from data regarding international partnerships, student and staff exchanges and the general participation of Romanian higher education in different EU programs (European Commission, 2018). Also, looking from a business perspective, integration of Romania in the EU common market can be called successful. When looking at one of the often-used indicators, foreign direct investments (FDI) in the Romanian economy, these investments were growing to levels way above the levels of before the EU accession (Ludosean, 2012). The years following the global financial \& economic crisis of 2008 brought a decrease in the flows of FDI to Romania, but followed by a steady recovery afterwards (National Bank of Romania, 2018). Arguably more importantly than the bare numbers, are the originating countries of these investments. In Romania's case, well over $90 \%$ of the FDI flows are from EU countries (National Bank of Romania, 2018), showing the strong connections of the Romanian economy with those from the EU. Also in terms of GDP growth, Romania is one of the fastest growing countries in the EU (Bayer, 2018) and the GINI coefficient of Romania is relatively high compared to Western European economies, but steadily falling (World Bank, 2019), indicating that income inequalities in society are becoming less extreme.

Still, notwithstanding the impressive economic performance of Romania as described in the previous paragraph and the growing participation of Romanian universities in EU networks, these developments do not yet show in the actual numbers of student mobility between Western European countries and Romania. At least not in the ERASMUS+ KA103 program, the largest and most well-known study mobility exchange program in Europe. In this study we did not look for other exchange programs, even though these do exist. Since the choice was made to focus on KA103, it also means that exchanges in vocational education as well as ERASMUS+ placement mobility are left out. The ERASMUS+ study mobility program is popularly seen as a measure of connectedness in terms of academic networks.

The overall picture is that there is less mobility of students from Western European countries to Romania and vice-versa than might be expected based on the number of mobile students in both countries. The authors took The Netherlands and Romania as example of two roughly equally sized EU member states in terms of population and determined the student 
mobility flows between the two countries and compared it with what could be expected based on the population of both countries. Since both countries have a roughly equal population, it could be expected that in both countries around 3\% of students would spend an exchange period in each other's country (see figure 1). The actual numbers as reported in the ERASMUS+ annual report for 2017, are for both countries not even close to this percentage, with a large gap especially from the Dutch side. Only 44 Dutch students spend an exchange period in Romania, out of a total of 13 783 ERASMUS+ participants (European Commission, 2018), no more than $0.3 \%$ of the total Dutch student mobility that year. From Romania 156 students went to the Netherlands, out of a total number of 9091 students (European Commission, 2018), or 1.7\% of the total KA103 Romanian student mobility.

Figure 1

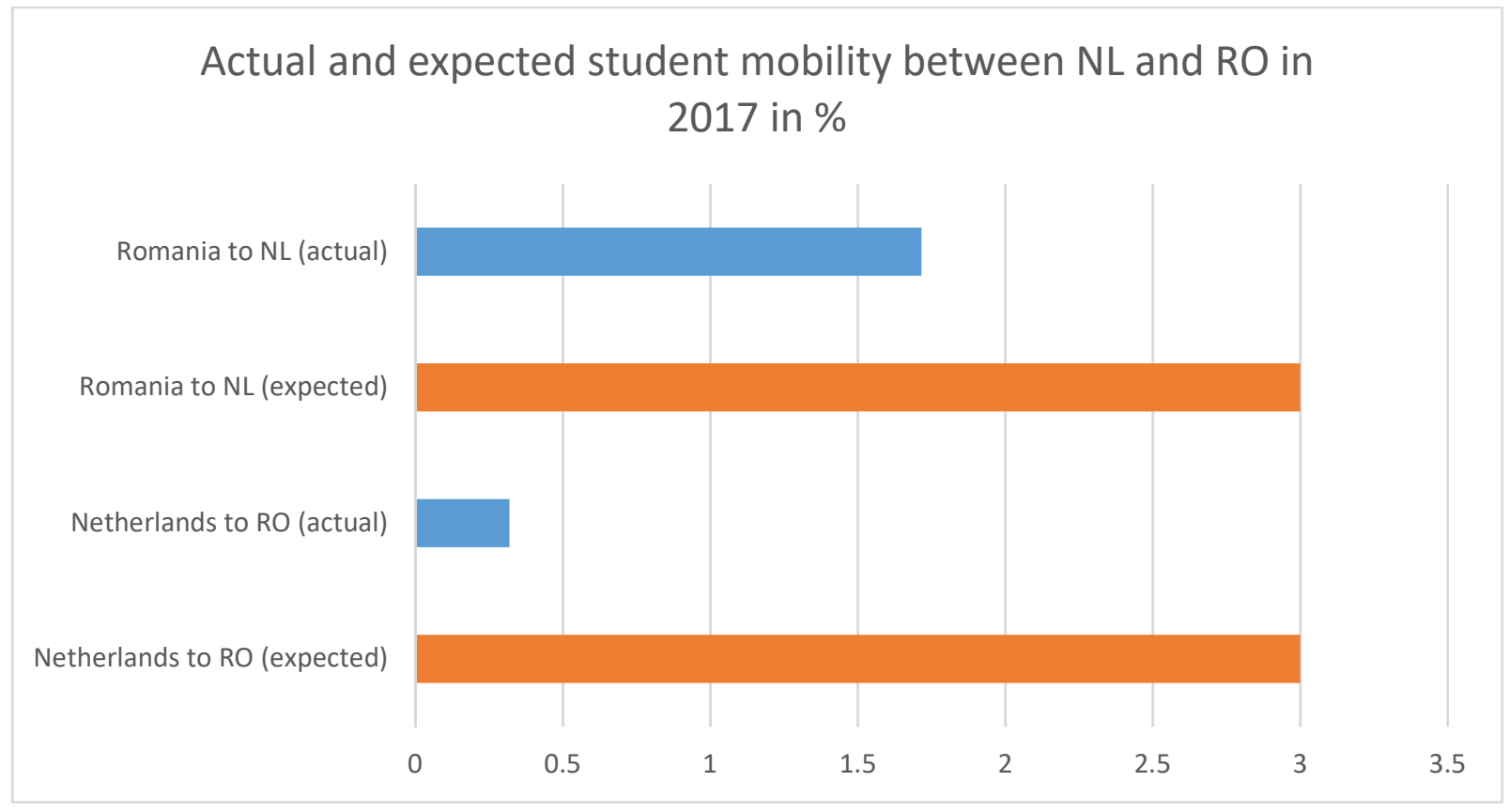

Source: The actual numbers are from ERASMUS+ Annual Report, European Commission, 2018

The same ERASMUS+ Annual Report shows that in general Romania is a net sender of students in the Erasmus program, meaning that Romanian universities are sending more students abroad than they attract foreign students to study in their institutions. When looking at the 
developments over the years 2007 - 2017, there is however a growth in the ratio of receiving and sending ERASMUS+ KA103 exchange students. The Receiving/Sending ratio (R/S-ratio) is calculated by dividing the number of incoming exchange students by the number of outgoing exchange students. If there is an equal number of incoming and outgoing students, the ratio will be 1 . The R/S-ratio for Romania in 2017 is 0.45 , meaning that Romania roughly sends twice as many students out than the country receives incoming students. For 2007 the R/S-ratio was 0.33 , meaning that the ratio was around three to one. It is therefore possible to conclude that the Romanian higher education has become relatively more attractive for foreign students. During this decade, the absolute numbers both of incoming and outgoing students have strongly increased. The number of outgoing students increased with $111 \%$ per year and the number of incoming students with no less than $192 \%$, although it must be noted that increases in small numbers in general cause large percentual growth. When comparing Romania with the other ERASMUS+ programme countries in terms of development of R/S-ratio and the development of this ratio during the 2007-2017 decade, it becomes clear that Romanian higher education has a lot of similarities with Slovakian and Bulgarian higher education institutions in terms of R/S-ratio and development. Other countries from Central/Eastern Europe such as Poland, Hungary, the Czech Republic and Slovenia all managed to move from net-sending countries into net-receiving countries, showing that these countries are seen by students as more attractive to spend an exchange period in. Gonzalez, Mesanza, and Mariel (2011) found in their study about student mobility flows that the cost of living, distance to the home country, university quality, the host country language and its climate are significant determinants for students to decide on where the spend their exchange period. Figure 2 shows the R/S-ratios of all ERASMUS+ KA103 programme countries and the development of this R/S-ratio over the decade 2007-2017. The R/S-ratio on the X-axis has a logarithmic scale, ranging from an R/S-ratio of 0.18 (Turkey), to 5.93 (Malta). Both Turkey and Malta are outliers, Turkey barely attracts incoming students and Malta receives almost 6 times more students than the country sends out. A positive value on the $\mathrm{Y}$-axis means an increase in the R/S-ratio over the decade 2007 to 2017 and a negative value means a decrease. Decreases in R/Sratios can occur when there are either less incoming students with a roughly similar number of outgoing students, or there are substantially more outgoing students with similar numbers of incoming students. The second case is happening for example in Denmark, the country that scores lowest on the R/S-ratio development. 
Figure 2

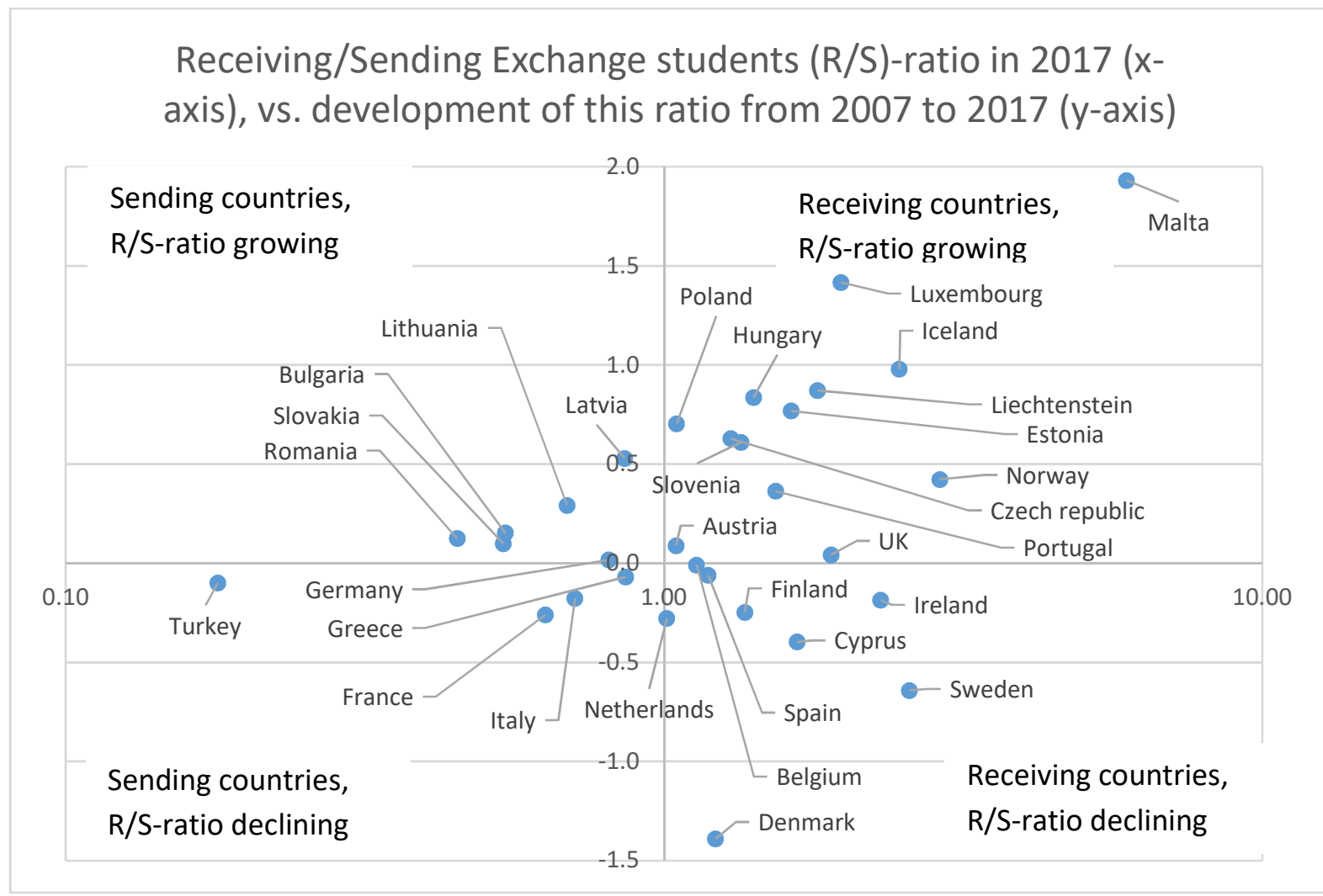

Source: ERASMUS+ Annual Report, European Commission, 2018

One of the other indicators to understand the development of Romanian integration in the European Union is the percentage of students that participate in student mobility periods. For all ERASMUS+ programme countries, this percentage is slightly above $1 \%$ per year. Given that a typical study period lasts for 4 to 5 years, it can be concluded that on average $4-5 \%$ of all students in the programme countries participate in a student mobility (European Commission, 2018). Figure 3 shows the yearly participation of students from all programme countries in the ERASMUS+ KA103 program. Romania scores slightly above average, and it can be expected that also in Romania $4-5 \%$ of the higher education students will have participated in an ERASMUS+ exchange period.

These data provide an insight in the matter of connectedness between Romania and other EU/ERASMUS + programme countries. As can be seen from figure 1, especially the mobility flows from Western Europe, for example from a country like the Netherlands to Romania are very small, 
but also vice versa, mobility flows are under average. There can and probably will be a myriad of reasons for this pattern, but the authors decided not to investigate in detail those reasons, but to take those as a given, yet unknown, fact of life and investigate from the available literature whether the popular idea that the ERASMUS+ study mobility is a measure of connectedness of universities internationally, holds. Furthermore, the authors decided to develop an educational intervention to try to connect Dutch and Romanian students in order to learn how to build effective international project cooperation within mixed teams of students from both countries. The goal of this project was to understand if students reported after a relatively short but intensive exchange project that their intercultural competences were increased and if they would like to pursue an exchange period or even career in the other country.

Figure 3

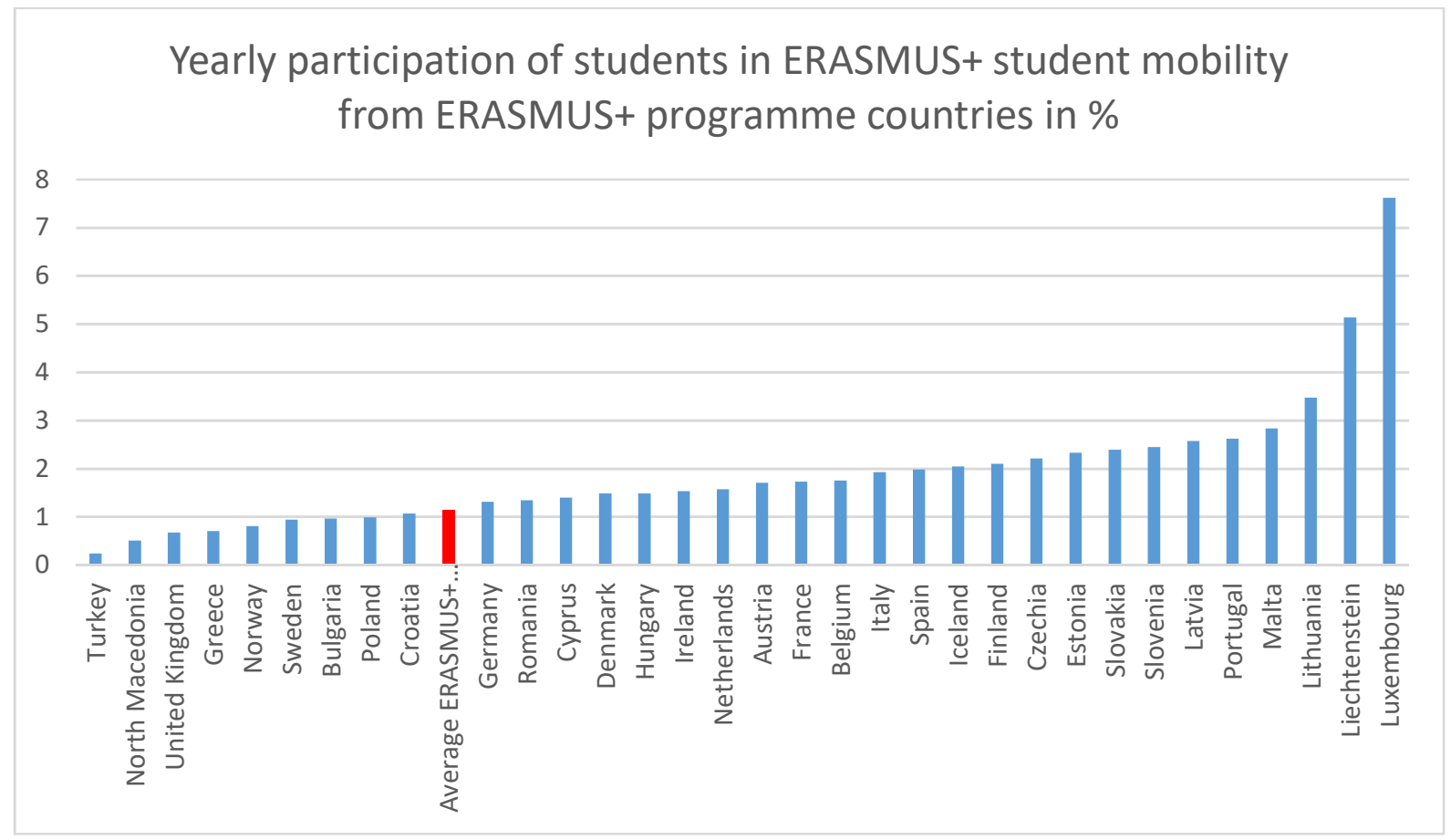

Source: Eurostat

\section{Theoretical Framework}

Study's into student exchanges are mostly limited to ERASMUS(+) exchanges, or other longer-term exchange periods. The European Commission already keeps track of statistics of the program, as could be seen in the introduction part of this paper. The idea behind the ERASMUS 
program is the so-called international integration theory (Sigalas, 2010), which states that because of more international cross-border contacts, in the right context, international integration and community building can occur, leading to sustained peace (Deutsch, 1966, 2015). Some authors have argued that at least partly some of these developments can be seen in Europe, where especially higher educated and white-collar workers also identify themselves as Europeans next to their own national identity (Fligstein, 2008). At the same time, Fligstein argues that a large group is mostly left out in the current EU policies, namely lower educated people and potentially at least some part of the middle class, which could lead to an actual widening of the gap between the perceived national identity and European identity.

Sigalas (2010) argues that it is assumed, but never proved that ERASMUS exchange programs are broadening the horizons of young people and are therefore helping with raising a European identity. Sigalas even found in his study the contrary, namely that participation in such an exchange program may even have adverse effects on feelings of Europeanness. He also concludes that it is unlikely that shorter study trips or tourism visits have any result on the development of a European identity among students. Therefore, the authors of this paper decided to develop a short-term targeted exchange program between the Netherlands and Romania aimed at bringing students together by challenging them with a practical business assignment that needs the skills of students from both countries in order to be completed successfully and test whether some effects can be found. Other authors however, like King and Ruiz-Gelices (2003), Recchi and Favell (2009), Van Mol (2013) and Mitchell (2015) did find - albeit sometimes modest - positive developments on European identity among ERAMUS participants.

There is other criticism possible on the way the exchange program is organised, when looking at its goal of building a more European identity. Mitchell (2015) argues that cultural isolationism is detrimental for European identity building. This cultural isolation quite often happens in practice, as it is rather common that groups of students from one university study together in another country. Mitchell further argues that given that around 5\% of EU students participate in an exchange program, no large developments among the general population of such programs can be expected. What is more, as Kuhn (2012) argues, the ERASMUS+ program misses its mark, as it appeals to the interest of those students who are already thinking internationally.

The effectiveness of short exchange programs and/or projects on "broadening the horizons of participants" of such projects seem to have been barely studied. A so-called ERASMUS 
Intensive Program comes closest to what the authors have designed in terms of educational intervention, although any ERASMUS Intensive Program is by design multilateral instead of bilateral as is the intervention studied in this paper. A search on Google Scholar and Scopus on "effectiveness of ERASMUS Intensive Programs" yielded a plethora of (conference) papers. However, all these papers were mainly dealing with an evaluation of the program itself, and not providing measurable quantitative data on how and how much the participating students have "broadened their horizon". Other authors, such as Racolța-Paina (2016) studied the Erasmus for Young Entrepreneurs program or, more general, the effects of entrepreneurship in Romania (Pop A.M, 2018). Yet, the Erasmus for Young Entrepreneurs program is not close to our educational intervention project because it is based mostly on individual participation and it is designed for a period of minimum two months.

\section{Educational intervention \& Research design}

Almost ten years ago the authors came with the idea to organize short term practice oriented international projects, for students from The Netherlands and Romania, particularly from Saxion University of Applied Sciences and Babes-Bolyai University. Our intention was to "broaden their horizon" and the solution we found was to mix up two groups of 12-15 students from each country, together with their teachers, in order to work on a specific assignment for one week, in smaller subgroups. This period might sound too short, but we thought of a one-week intensive work, with preparation in advance (couple of months in advance). At the end of that week the students had to present the results of their work to the client, either from a private company or from public institutions.

The content of these short-term international projects was related to structured problem solving suggested by businesses and/or societal organizations. Some examples of short-term projects that we organized for students along the years are:

- Courtyard development in the city of Cluj-Napoca (new functions for courtyards in the centre);

- Some embankment development project (river to the city), related to the preparation of the candidature for European cultural capital;

- Ethnographic park of Cluj-Napoca (solution for revitalization of the park and museum); 
- $\quad$ Urban mobility in Cluj-Napoca (development of bicycle transport network);

- $\quad$ European cultural capital candidature of Cluj-Napoca project (several issues);

- $\quad$ Firemen's tower (renovating \& finding a new use);

- Aegon Pensions Romania (comparative analysis of the Dutch and Romanian pension systems);

- Entrasol company NL, innovative nano-carbon tube heating (prospection and analysis of the Romanian market).

Among the involved partners and stakeholders were public or societal organizations (eg Cluj-Napoca City Hall, Dutch Consulate in Cluj, Asociația Cluj 2021-Capitală Culturală Europeană, The Ethnographic park etc.) and private companies from the Netherland or Romania (eg Entrasol, Aegon etc.) to whom the students presented their results in the last day of each project.

In order to measure the results of our educational intervention through these short-term projects, the authors decided to apply questionnaires to the students before the beginning and after the end of selected projects. Like this we measured the competences of the students before and after the project (pre-test + post-test) in an interval of time of 3 weeks between the two tests. The students were asked about their intentions to start their own international business, if they desire an international career, if they feel comfortable working with people from different cultures in international project management. Over the two years period of research we had 55 respondent students ( $\mathrm{n}=55$ ) organized in teams of mixed nationalities (mainly Dutch and Romanians, but also a few other nationalities) and mixed disciplines (urban planning, management, constructions, European studies, architectures etc). A few years ago we also conducted qualitative interviews with students about their participation in the projects at that time and the results and analysis are in an already published paper of Bazen, Duma, and Stamate (2015) with one conclusion clearly expressed by one the students : "A lot of prejudices from both sides were busted during this week".

\section{Analysis and results}

The results of the questionnaires are summarized in the chart below, figure no.4. At a first glance, we can observe that most of the indicators show a slight decrease from the pre-test to posttest answers. We can explain this by the fact that the students were too optimistic in advance and they most probably realized during the projects that working in or with a different culture is more 
complicated than it looks at the beginning. At the same time, when asked "Overlooking everything in terms of how you developed yourself, what grade would you give this project on a scale of 110 ?", they gave a good grade: average grade 8.4.

If we are looking at each indicator individually, both ways, in absolute value and in the dynamic, we can find some interesting results. The first indicator, related to the skills required to work in international projects, had the higher score in pre-test showing that the students tend to be well overconfident before starting the project, yet becoming more aware of what is necessary after the project was complete.

Figure 4

\section{Development of perceived competences}

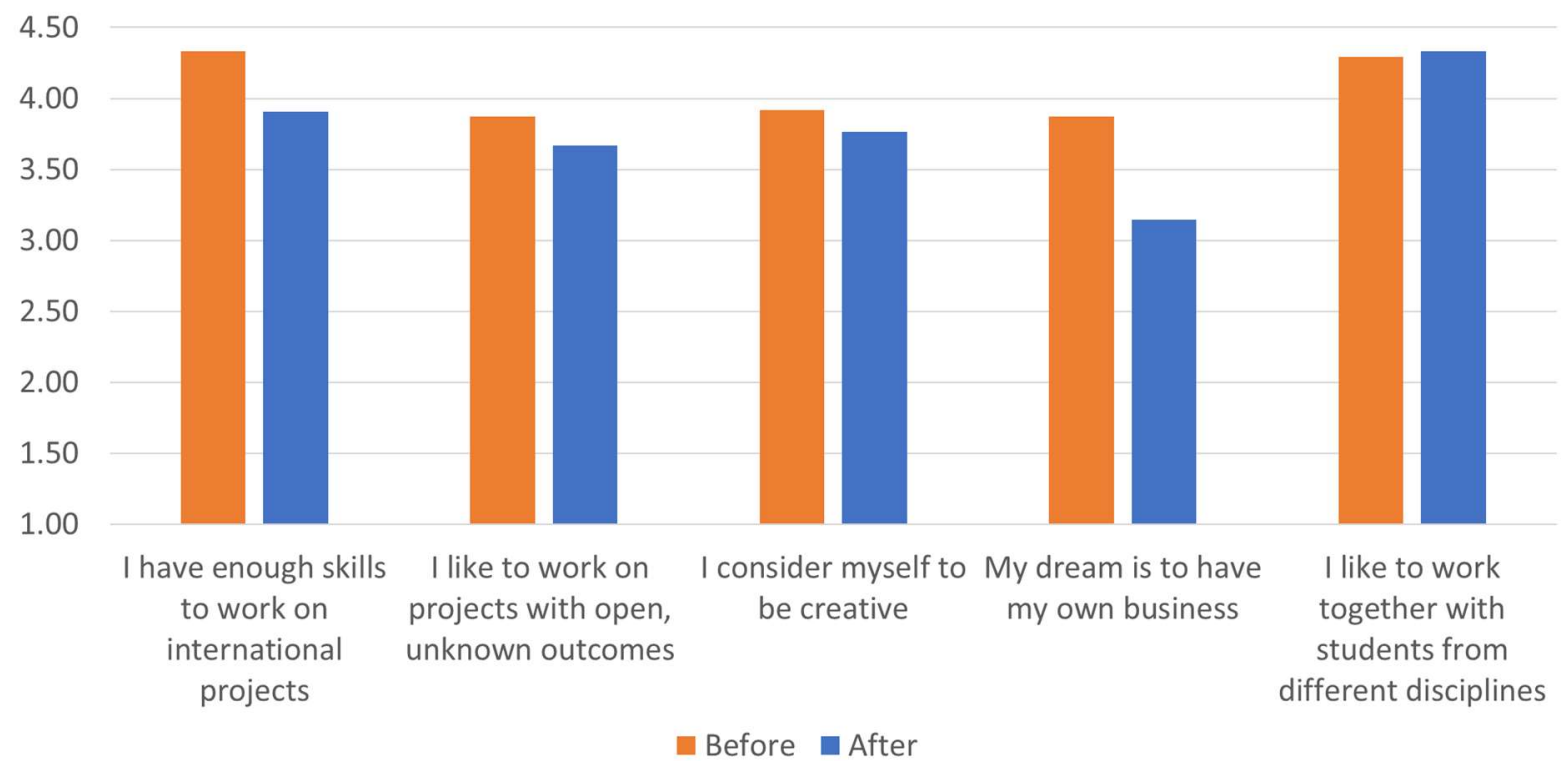

Source: authors' calculations.

When they are asked if they like to work on projects with open and unknown outcomes, the students are less confident already from the pre-test compared to the previous question. Faced with uncertainty during the project and its outcomes, their confidence is decreasing even more, showing a fading uncertainty tolerance.

Regarding their own creativity there is not much change in the student's perception, before and after the project, probably because the students were constantly encouraged to come with ideas 
and proposal at all stages of the project. Though, the largest drop between pre-test and post-test is registered at the question related to their dream to start a business, when the students become more realistic after they worked in an international project with a real assignment for a real client and they realize all the complexity of it.

Concerning the last indicator, we can observe that students are very comfortable working in multi-disciplinary teams (architects, management, archaeology, European studies, entrepreneurship, civil engineers, urban planners, tourism). This fact is demonstrated not just by the high score (close to 4.5), but especially by the fact that this the only indicator that registered an increase in value from the pre-test to post-test.

\section{Conclusions}

It is well known that for many people it is difficult to adapt or to work in or with a different culture, but due to globalization, that is already a fact for many years now - not just a premise, we all have to learn how to improve the necessary skills for this. The same is true for the 'Millennials' or the 'iGeneration', that are currently our students. Apparently, there is a paradox here. On the one hand, due to the internet and the social networks, the Millennials think that they understand very well other cultures, they have many friends abroad (usually, e-friends) and they will have no difficulties to study or to work in another country. On the other hand, they are not really prepared or willing to leave their comfort zone in order to go to study abroad and for this we can just take a look at the low numbers related to the yearly participation of students in ERASMUS+ student mobility from programme countries (see figure no.3), despite the fact that this program is very accessible and generous. Our research tends to confirm this, by showing a decrease in almost all the indicators related to how the students perceive themselves in the pre-test and post-test.

We believe that this type of educational intervention, in the form of short-term international projects, is helping the students to fill the gap between what they think and what is the reality 'in the field' and, before anything else, to break the ice. As a matter of fact, being involved in the Erasmus departments at our faculties, we observed that the students who went once in Erasmus, very often they want, and they do return for another semester or/and later at the master or during their $\mathrm{PhD}$. Same was true after our projects, most of the students reported being very interested to come again and work on short term international projects or to do an internship abroad. Moreover, we think that we managed to bridge between foreign and local companies/organizations and 
students in order to fill the gap between theory and practice in an international context. In fact, we have always received positive feedback from the companies or organizations that were involved in our projects and students were invited for (paid) internships and some of them got hired later on (e.g. at Aegon).

Our intention is to continue these short-term projects in the future and maybe to develop it in new directions, for example to see what happens if this type of educational intervention would be compulsory. For the research purpose, would be interesting to further investigate if there is a selection bias in participants and the long-term effects of these collaborations.

\section{References}

1. BAYER, L. (2018) Europe's eastern tigers roar ahead. Politico. Retrieved from https://www.politico.eu/article/central-and-eastern-eu-gdp-growth-economies/

2. BAZEN, J. C., DUMA, F. S. and STAMATE, D. (2015) International project education of the future? Measuring effectiveness of short-term international exchange projects. Paper presented at the Mokslo taikomieji tyrimai Kauno kolegijoje, Kaunas. Lithuania.

3. DEUTSCH, K. W. (1966) Nationalism and social communication: an inquiry into the foundations of nationality: M.I.T. Press.

4. DEUTSCH, K. W. (2015) Political Community and the North American Area: Princeton University Press.

5. EUROPEAN COMMISSION. (2018) Erasmus + annual report 2017. Retrieved from Brussels: https://ec.europa.eu/programmes/erasmus-plus/about/statistics en

6. FLIGSTEIN, N. (2008) Euroclash: The EU, European identity, and the future of Europe: Oxford University Press.

7. GONZALEZ, C. R., MESANZA, R. B. and MARIEL, P. (2011) The determinants of international student mobility flows: an empirical study on the Erasmus programme. Higher Education, 62(4), 413-430. doi:10.1007/s10734-010-9396-5

8. KING, R. and RUIZ-GELICES, E. (2003) International student migration and the European 'year abroad': effects on European identity and subsequent migration behaviour. International Journal of Population Geography, 9(3), 229-252. 
9. KUHN, T. (2012) Why Educational Exchange Programmes Miss Their Mark: CrossBorder Mobility, Education and European Identity. Jcms-Journal of Common Market Studies, 50(6), 994-1010. doi:10.1111/j.1468-5965.2012.02286.x

10. LUDOSEAN, B. M. (2012) A VAR analysis of the connection between FDI and economic growth in Romania. Theoretical and Applied Economics, 19(575), 115-130.

11. MITCHELL, K. (2015) Rethinking the 'Erasmus Effect' on European Identity. JcmsJournal of Common Market Studies, 53(2), 330-348. doi:10.1111/jcms.12152

12. NATIONAL BANK OF ROMANIA (2018) Foreign direct investment in Romania. Retrieved from Bucharest: https://www.bnr.ro/files/d/Pubs_en/FDI/eFDI2017.pdf

13. POP, A.M. (2018) The evolution of the Romanian SMEs after Romania's integration in the European Union Structures, On-line Journal Modelling the New Europe, Issue 27, September, pp.148-159.

14. RACOLT,A-PAINA, N. D. (2016) The European Single Market: opportunities for entrepreneurs-The case of Erasmus for Young Entrepreneurs. Studia Universitatis Babes-Bolyai-Studia Europaea, 61(4), 21-41.

15. RECCHI, E. and FAVELL, A. (2009) Pioneers of European Integration: Citizenship and Mobility in the EU: Edward Elgar Publishing, Incorporated.

16. SIGALAS, E. (2010) Cross-border mobility and European identity: The effectiveness of intergroup contact during the ERASMUS year abroad. European Union Politics, 11(2), 241-265.

17. VAN MOL, C. (2013) Intra-European Student Mobility and European Identity: A Successful Marriage? Population Space and Place, 19(2), 209-222. doi:10.1002/psp.1752

18. WORLD BANK (2019) GINI index (World Bank estimate). Retrieved from https://data. worldbank.org/indicator/SI.POV.GINI?contextual=region\&end=2015\&lo $\underline{\text { cations }=\text { RO\&start }=1989 \& \text { view }=\text { chart }}$ 